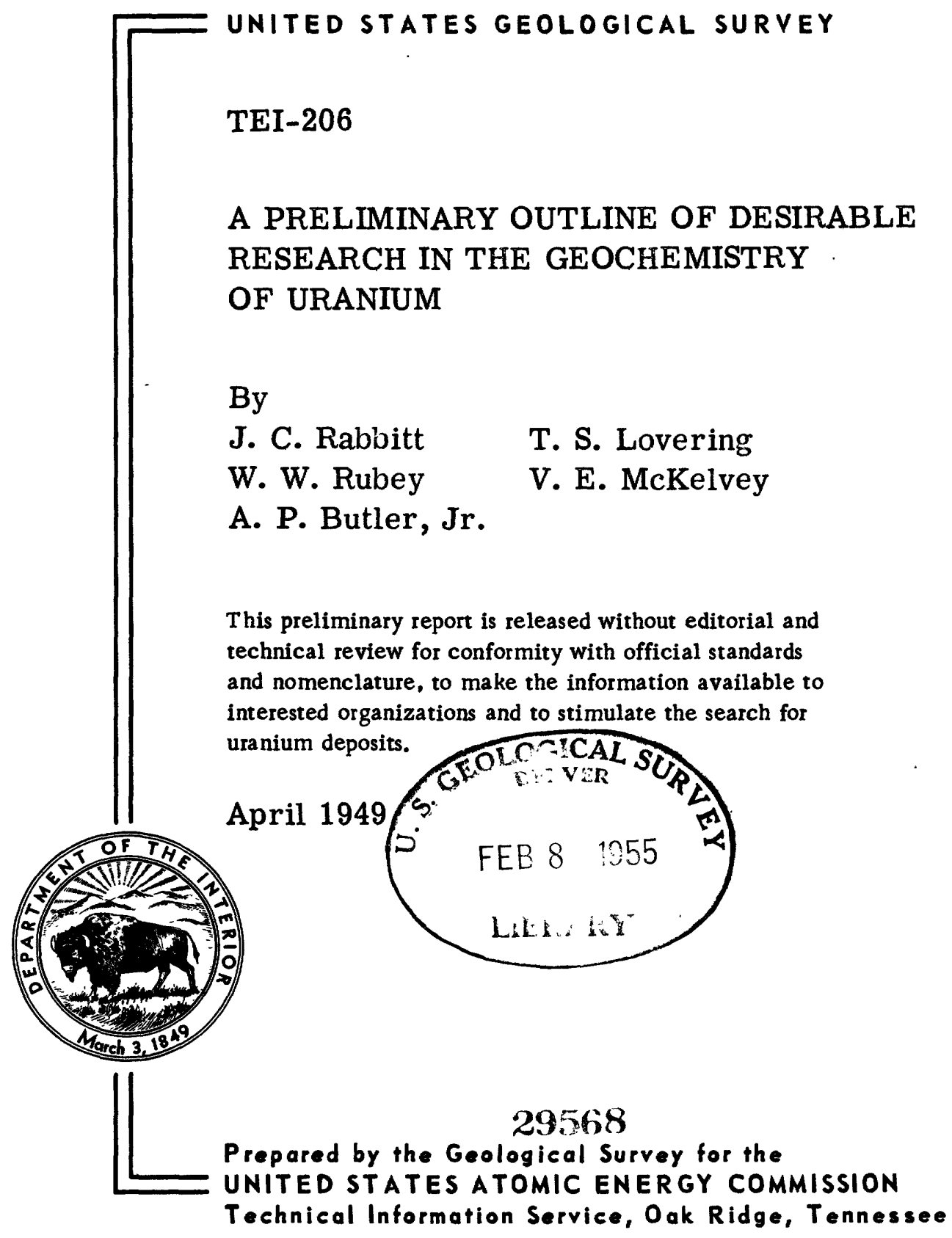




\section{GEOLOGY AND MINERALOGY}

Reproduced direct from copy as submitted to this office.

This report concerns work done on behalf of the Division of Raw Materials of the U.S. Atomic Energy Commission. 
CONTENTS

$\underline{\text { Page }}$

Abstract............................... 4

Introduction........................... 4

Outline of research...................... 5

Specific topics and projects................. 7 


\section{A PRELIMINARY OUTLINE OF DESIRABLE RESEARCH}

IN THE GEOCHEMISTRY OF URANTUM

\section{By}

J. C. Rabbitt, W。W Rubey, A。P.Butler, Jr。g $\mathrm{T}$. So Lovering, and $\mathrm{V}$ 。 $\mathrm{E}$. McKelvey

\section{ABSTRACT}

This report outlines fields of study for a program of research in the geochemistry of uranium. These fields of study are as follows: I. Review of the present status of the geochemistry of uranium and the geology of uranium deposits. II. Abundance, distribution, and mode of occurrence of uranium in the solid materials of the earth's crust. III. Abundance, distribution, and mode of occurrence of uranium in waters. IV. Abundance, distribution, and mode of occurrence of uranium in gases. V. Processes and conditions affecting the abundance, distribution, and mode of occurrence of uranium. VI. MineralOgy, chemistry, and radioactivity of uranium. VII。 "Geochemical" prospecting for uranium.

Various specific topics and projects that apply to these fields of study are suggested. Many of the suggested projects fall within the scope of Geological Survey functions and facilities, but participation by other organizations would be necessary on others.

\section{INTRODUCTION}

The following outline covers the fields of study for an expanded program of research in the geochemistry of uranium. The outline is 
generalised but is followed by a list of toples and projecto thit: It Into the cotiline itself. Heading and sub-heading th the outline are followed by numbered references to the appropriate toplce and projects. The word uranive as used here would be interpreted to include the other radioactire elements and their daughter products.

\section{OUPLIN OF RESTHRG}

I. Devion of the present tatus of the geochemistry of uranium and the coolog of uranium deposits (see project 1).

II. Abandance, dintribution, and mode of occarrence of uranium in the -011d materials of the earth's crust.

1. Igneous rocks (see projects $2,3,4,5,7,8,9,24$ ).

B. Sedimentary rocke (see projecte 6, 24).

C. Notamorphic rocks (see projects 5, 24).

D. Toins (see projects $2,3,4,5,7$ ).

I. S011. (see projects $2,9,24$ )。

T. AnImal and plant remains and derived deposits (noe project 10).

G. Differences of abundance, distribution, and wode of occurrence in the above materials during goologic time (wee projocts 17,20$)$.

III. Abundance, distribution, and mode of occurrence of urantum in water.

1. Oceans and seas (see project 11).

B. Salt and brackish inland seas and lakes (see project 12 ).

C. Blvers and freshwater lares (seo project 13).

D. Groundwater, springs, and furenile water (see project 14

I7. Abundance, distribution, and mode of occurrence of uranium in gases.

1. The atmosphere (nee project 15). 
B. Volcanic gases (see project 16).

C. Intrapped gases (see project 16).

V. Processes and conditions affecting the abundance, distribution and mode of occurrence of uranium.

A. Physicomchemical procẹsses

1. Source in the primal crust of the earth (see project 17).

2. Magmatic differentiation including transportation and preciptation under hydrothermal conditions (see prosects $5.8,8)$.

3. Transportation and precipitation under surface and near-surface conditions (see projects 6,14 ).

4. Oxidation and weathering (see project 9 ).

B. Activities of plants and animals (see project 10).

C. Iithology and geologic structure (see project 8).

VI. Mineralogy, chemistry, and radioactivity of uranium.

A. Review and reclassification of the uranium minerals (see projects 1,21 ).

B. Is otope studies (see projects 10, 15, 17, 18, 19, 20).

C. Radioactive equilibrium studies (see projects $15,19,20$ ).

D. Synthesis of uranium minerals (see projects 21, 22).

I. Relation between abundance of different uranium mineral species and geologic age (see projects $17,20,21$ ).

F. Relation of uranium to trace and essential elements in rocks and minerals (see projects $2,23,24$ ).

G. Chemistry of uranium in solutions (see projects 9, 11, 12, 22)。

H. Role of uranium in mineral structures (see projects 22 , 23, 24)。 
VII. "GeochemicaI" prospecting for uranium. (See projects 5, 10, 13.)

\section{SPECIFIC TOPICS AND PROJECTS}

For each topic and project there is given a short title and (where applicable) a condensed description of its usefulness to the exploration program. This is followed in parentheses by the number or numbers of the heading or headings in the outline to which the topic or project applies.

Many of the suggested projects fall within the scope of Geological Survey functions and facilities. Participation by other organizations would be necessary on others. It would be highly desirabie in such circumstances that there be close cooperation between the Survey and the other agency; the Survey, because of its large field and laboratory organization would furnish information, advice, and assistance.

1. Lit erature reviews:--Lit erature reviews, done by competent geologists and mineralogists as full-time projects, should be made for such topics as, (I) the geology of high-grade uranium deposits in the world, (2) the geology and geochemistry of uranium in marine sediments, (3) the carnotite type of deposits, (4) uranium in pegmatites and other igneous rocks, (5) the mineralogy of uranium. Such reviews would be basic to the work of most if not all of the projects. (See $I, V I A_{0}$ )

2. Distribution of trace elements and essential elements in uranium ores and pegmatites.--This would aid in finding concealed and other types of ore deposits. Such studies are being made at Majuba Hill, Nevada, and should be made in the "breccia reefs" of the Colorado Front Range, where these "reefs" (quartz-hematite-fluorite veins) 
$\because$ are assoclated. mith Oo-NI, Ag, and fluorito deposits. (Seo II A, II $D_{g}$ II II, VI $\mathrm{I}$ )

3. Relation of pitchblende deposits to diabase dikes-many pitchblende and similar deposits are associated with diabase dikes. Such dikes and associated folsic intrusives, and imilar bodies in northern Minnesota, Wisconsin, and Michigan should be studied for their uranium content to see if this association has any significance. (See II A, II D).

4. Paragenetic study of domestic pitchblende deposits.--Determination of mineralogical association in such deposits to find any significant associations which would provido guides to similar deposits. (See II A, II D).

5. Distribution of uranium and derived elements around known deposits.The wall rock, country rock, and metamorphic aureoles around known deposits should be studied to provide basic data for prospecting. (See II A, II C, II D, VAZ, VII).

6. Uranium in modern marine sediments. $\rightarrow$ A study of the distribution of uranium and its physicomchemical environment in modern marine sediments would be useful in the black shale and phosphate program and in the search for new similar deposits. For example, such sediments are now forming in the Gulf of Mexico off the west coast of Florida and the aid of an oceanographic institution might be enlisted in studying these deposits. (See II B, $\mathrm{VA3}$ ).

7. Depth relations of uranium minerals. - The distribution of uranium minerals in the hydrothermal depth zones would provide clues as to what type of such deposits might be most favorable for uranium. (See II A, II D). 
8. Monazite.--Distribution of uranium in monazites, of monazite in granites, and of monazite-bearing granites as part of the study of and search for monazite deposits. Monazite as a possible economic source of uranium should be investigated. (See II A, $\nabla$ A2, $\nabla$ C).

9. Differences between uranium content of soils and their parent rocks.- This would shed light on the mobility of uranium in solutions, the effect of weathering on uranium minerals, and the usefulness of tracing the uranium in soils to its source. (See II $A$, II $\mathbb{E}, \nabla \mathbb{A}, \mathrm{VI} G$ )。

10. Mechanisms of utilization and concentration of uranium by organ= 1sms.-Determine the extent to which organisms concentrate uranium, thorium, and radium, and do they do so selectively as to isotopes? Determine whether uranium occurs in natural organic compounds. Determine whether organisms aid in precipitating uranium from solution. Do either chemical or radiation effects of the ingestion of uranium result in any detectable differences in flora as a guide to prospecting? (See II F, V B, VI B, VII).

11. Uranium in sea water.-More work should be done on the abundance of uranium (and thorium and radium in particular) in sea water. The chemistry of these elements in sea water and the role of organisms in their precipitation (see project 10) should be investigated. The ratio $\mathrm{U} / \mathrm{Th}$ in sea water as contrasted to that in rocks should be studied. (See III A, VI G).

12. Searles Lake and similar saline deposits.--Many such deposits might be expected to show concentrations of uranium but work to date seems to indicate that they do not. This lack of concentration 
should be studied to provide clues as to how and where the element is subtracted from surface waters and where it is concentrated as
a result of this subtraction。 (See III $B_{9}$ VI Go)

13. Radioactivity of surface waters, - The radioactivity of rivers, lakes, and other surfice waters should be determined to find any significant concentrations which might indicate sources of uranium. (See III $C_{2}$ VII.)

14. Radiosctivity of ground water. $=$ The significance of radioactive cround water as an indicator of sources of uranium should be inrestigeted. Radioactive springs would be of special interest in such a study. (See III $D_{3} \nabla$ 13.)

15. Intensity of radiation in the atmosphere-The appication of airborne radiation detectors to correlate unusual concentrations of radiation in the air over uranium deposits should be studied as an ald in airborne prospecting。( Soe IV $A_{9}$ VI $B_{9}$ VI $C_{0}$ )

16. Hellum problem. - This problem comprises such studies as, (1) the relation of helium to the uranium content of rocks, (2) the movement of helium through different types of rocks, (3) further work on the retention and loss of helium by different rocks and minerals. These are a few of the studies involved in the helium problem a problea the solution of which will aid in prospecting for concent rations of uranium, perticularly in concealed deposits. (See IV $B_{9}$ IV C.)

17. Isotopes.-A systematic study of isotopes in geology should be undertaken. For instance, we should know the significant isotope content of uranium minerals and meteorites; the composition of meteorites is the best index we have to the composition of the 
interior of the earth. Studies on meteorites are being done elsewhere but much of the isotope program can be done in the Survey. (See II G, V AI, VI B, VI E。)

18. Isotope ratio $U^{238} / U^{235} \cdot-1$ redetermination of the relative abundance of these isotopes should be made on rocks and minerals of widely different geological ages. A continuing program of determining this ratio on all materials of significance in the exploration program should be set up. The finding of any significant concentrations of $\mathrm{U}^{235}$ would be of great importance. (See VI B.)

19. Radioactive equilibrium studies.--Studies similar to those on the carnotites should be undertaken on other suitable deposits. This would provide basic data on the geochemistry of uranium. It would also be of the greatest aid in prospecting; for instance, it would help in determining where uranium might be leached and where it might be concentrated. (See VI B, VI C.)

20. Natural fission.--The whole question of the possibilities of natural fission should be investigated. Evidence of natural fission would have a profound bearing on such problems as, (1) age determinations, (2) heat balance in the earth's crust, (3) concentration of rare earths. (See II G, VI B, VI C, VI E。)

21. Systematic mineralogy of uranium.--This broad investigation is now in progress in the Survey but should be broadened and intensified (both in the Survey and in other agencies) to include work on the synthesis of the more important uranium minerals. Examples of such work are the studies by the Survey of the synthesis of carnotite, tyuyamunite, and related minerals, and the studies of 
the synthesis of uranium phosphate at Battelle. (See VI $A_{9}$ VI $D_{9}$ VI E。)

22. Uranium substitution in mineral structures.--This study would include such problems as base exchange, substitution of uranium for other elements in mineral structures, and adsorption of uranium by different minerals. This would aid research in process metallurgy and would provide basic knowledge as to the mineralogy of uranium. (See VI D, VI G, VI Ho)

23. Effects of uranium content of minerals.--Further studies should be made of pleochroic halos, smoky quartz, and related phenomena, and metamict structures to determine the effect of uranium on the minerals in which it occurs. (See VI F, VI Ho)

24. The geology and geochemistry of rare elements.-A study of such elements as $\mathrm{Be}_{9} \mathrm{Ga}_{2} \mathrm{Hf}_{9}$ and $\mathrm{Rb}$ might be of interest to the Atomic Energy Program. This would mean the present mill products program of the Survey, expanded to include other rare elements and diverse rock types。(See II A. II $\mathrm{B}_{2}$ II $\mathrm{C}$, II E, VI F, VI Ho)

These 24 topics and projects are a cross section of studies that should be a part of a program of research in the geochemistry of uranium. 